\title{
Assessment of patient-ventilator breath contribution during neurally adjusted ventilatory assist in patients with acute respiratory failure
}

Ling Liu', Songqiao Liu', Jianfeng Xie', Yi Yang ${ }^{1}$, Arthur S Slutsky ${ }^{2,3}$, Jennifer Beck²,4 Christer Sinderby ${ }^{2,3}$ and Haibo Qiu* ${ }^{1 *}$

\begin{abstract}
Introduction: We previously showed in animals that the ratio of inspired tidal volume $\left(\mathrm{Vt}_{\text {insp }}\right)$ to inspiratory peak electrical activity of the diaphragm (EAdi ${ }_{p k}$ ) can be used to quantify the respective patient and ventilator breath contributions (PVBCs) during neurally adjusted ventilatory assist (NAVA). The PVBC index has not been tested clinically.
\end{abstract}

Methods: We studied 12 intubated and mechanically ventilated patients with acute respiratory failure and

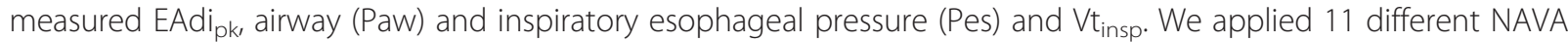
levels, increasing them every 3 minutes in steps of $0.3 \mathrm{~cm} \mathrm{H} \mathrm{H}_{2} \mathrm{O} / \mu \mathrm{V}$ from 0 to $3.0 \mathrm{cmH}_{2} \mathrm{O} / \mu \mathrm{V}$. At each NAVA level, one breath was non-assisted (NAVA level 0). PVBC indices were calculated by relating $V \mathrm{t}_{\text {insp }} / \mathrm{EAdi}_{\mathrm{pk}}$ of the non-assisted breath to $\mathrm{Vt}_{\mathrm{ins}} / \mathrm{EAdi}_{\mathrm{pk}}$ of the assisted breath(s) using one ( ${ }^{\mathrm{N} 1} \mathrm{PVBC}$ ) or the mean value of five preceding assisted breaths $\left({ }^{X} \mathrm{PVBC}\right)$. During assisted breaths, inspiratory changes in Pes ( $\triangle \mathrm{Pes}$ ) and transpulmonary ( $\left.\Delta \mathrm{Ptp}\right)$ pressures were used to calculate the relative contribution of patient to total inspiratory lung-distending pressures ( $\Delta \mathrm{Pes} / \Delta \mathrm{Ptp})$. Matching of respiratory drive indices and squaring of the PVBC was evaluated for their effect on the correlation between PVBC and $\Delta$ Pes/ $\Delta$ Ptp. Linear regression analysis and Bland-Altman analysis were applied to compare indices.

Results: Using an average of five assisted breaths prior to the non-assisted breath and squaring the PVBC $\left({ }^{\times 5} P V B C^{2}\right)$ improved determination coefficients $(P<0.05)$, adjusted the regression slope and intercept between PVBC and $\triangle P e s /$ $\Delta$ Ptp toward identity $(P<0.05)$ and reduced bias $(P<0.05)$. Matching EAdi pk $_{\text {b }}$ between non-assisted and assisted breaths within the range of 0.77 to 1.30 improved the relationship between ${ }^{X 5} \mathrm{PVBC}^{2}$ and $\Delta \mathrm{Pes} / \Delta \mathrm{Ptp}(P<0.05)$ and abolished the need for EAdi normalization in the PVBC calculation $\left(R^{2}=0.96\right.$; bias $=0.16 \pm 0.06$; precision $=0.33 \pm 0.08$ ( mean and $95 \%$ confidence interval)).

Conclusions: This clinical study confirms previous experimental results showing that the $\mathrm{PVBC}^{2}$ predicts the contribution of the inspiratory muscles versus that of the ventilator during NAVA, when differences in effort (EAdi) between non-assisted and assisted breaths are limited. PVBC could help to quantify and standardize the adjustment of the level of assist, and hence reduce the risks of excessive ventilatory assist in patients.

Trial registration: ClinicalTrials.gov NCT01663480. Registered 9 August 2012.

\footnotetext{
*Correspondence: haiboq2000@163.com

'Department of Critical Care Medicine, Zhongda Hospital, Southeast

University, School of Medicine, 87 Dingjiagiao Street, Nanjing 210009, China

Full list of author information is available at the end of the article
} 


\section{Introduction}

The aim of today's approach to mechanical ventilation is generally to achieve more spontaneous breathing and greater use of so-called partial ventilatory assist, whereby the ventilator and the patient share the inspiratory work. In order for partial ventilatory assist to be efficient in patients who are spontaneously breathing, it must be synchronized in terms of both its timing and its magnitude. However, conventional modes of partial ventilatory assist are often associated with patient-ventilator asynchrony or dyssynchrony [1-3]. Neurally adjusted ventilatory assist (NAVA) is a mode that uses the electrical activity of the diaphragm (EAdi) to synchronize ventilation, and it has been demonstrated to fulfill these requirements [4-11].

One of the biggest unknowns with the use of partial ventilatory assist is the relative contribution of patient effort and ventilator assistance during a breath. An index for quantifying the respective patient and ventilator breath contributions (PVBCs) using an experimental model of acute respiratory failure (ARF) in animals ventilated with NAVA was recently published [12]. In the PVBC index, the ratio of inspiratory tidal volume $\left(\mathrm{Vt}_{\text {insp }}\right)$ and peak inspiratory electrical activity of the diaphragm (EAdi $\left.i_{p k}\right)$ was used for both an assisted breath and a subsequent breath with no assistance [12].

To validate the PVBC index in our previous study [12], we measured esophageal pressure (Pes) as reflecting pleural pressure and representing the patient's inspiratory effort. After measuring the airway pressure (Paw) delivered by the ventilator, we calculated the transpulmonary pressure (Ptp) as Paw - Pes to quantify the total pressure applied to distend the lungs. The ratio of inspiratory changes in Pes and Ptp ( $\Delta \mathrm{Pes} / \Delta \mathrm{Ptp})$ was used to represent the fraction/contribution of esophageal pressure (patient) to total inspiratory pressure (patient + ventilator) during NAVA. In our previous experimental study [12], the PVBC index was found to correlate closely to $\triangle \mathrm{Pes} / \Delta \mathrm{Ptp}$, and it was found that squaring of the PVBC produced a near-perfect linear relationship.

On the basis of the findings of our previous experimental study, we designed the present study to evaluate the PVBC index in humans with ARF. Similar to our previous work in animals [12], the underlying hypothesis was that a simple measurement of $\mathrm{Vt}_{\mathrm{insp}}$ and $\mathrm{EAdi}_{\mathrm{pk}}$ between a non-assisted breath and the preceding ventilatorassisted breath(s) would allow the calculation of the PVBC index in humans. We carried out the study with the following assumptions. (1) EAdi $\mathrm{pk}_{\mathrm{p}}$ during an inspiration reflects neural demand to generate $\mathrm{Vt}_{\text {insp }}$. (2) If adding synchronized assistance to the patient's neural inspiratory demand, the resulting $\mathrm{Vt}_{\text {insp }}$ depends on the sum of patient and ventilator pressure contribution. (3) If the neural inspiratory demands are different for two consecutive breaths, normalizing the $\mathrm{Vt}_{\mathrm{insp}}$ to $\mathrm{EAdi}_{\mathrm{pk}}\left(\mathrm{Vt}_{\mathrm{insp}} / \mathrm{EAdi}_{\mathrm{pk}}\right.$, in units of $1 / \mu \mathrm{V})$, a PVBC index can be constructed using the ratio of $\mathrm{Vt}_{\mathrm{insp}} / \mathrm{EAdi}_{\mathrm{pk}}$ without ventilatory assistance to $\mathrm{Vt}_{\text {insp }} / \mathrm{EAdi}_{\mathrm{pk}}$ with assistance (that is, $\left(\mathrm{Vt}_{\mathrm{insp}} / \mathrm{EAdi}_{\mathrm{pk}}\right)_{\text {no-assist }} /$ $\left.\left(\mathrm{Vt}_{\text {insp }} / \Delta \mathrm{EAdi}_{\mathrm{pk}}\right)_{\text {assist }}\right)$; a PVBC index close to 1 suggests that $\mathrm{Vt}_{\text {insp }}$ is generated by the patient, whereas a PVBC index close to 0 indicates that $\mathrm{Vt}_{\text {insp }}$ is generated by the ventilator. (5) If the patient's neural inspiratory demand is similar during both non-assisted and assisted breaths, the ratio of $\mathrm{Vt}_{\text {insp }}$ alone during the non-assisted and assisted breaths should reflect the relative contribution of the patient vis-à-vis patient + ventilator.

If reliable, PVBC could help to quantify and standardize the adjustment of the level of ventilatory assistance and reduce the risks of excessive ventilatory assistance in patients.

\section{Material and methods}

This trial was conducted in a 30-bed general intensive care unit (ICU) of a teaching hospital affiliated with Southeast University in China. The protocol was approved by the Institutional Ethics Committee of Zhongda Hospital (approval number 2010ZDLL018.0), and informed consent was obtained from the patients or their next of kin. The trial is registered at ClinicalTrials.gov (NCT01663480).

\section{Patients}

Patients were eligible for inclusion if they were (1) intubated or tracheotomized, (2) undergoing assisted mechanical ventilation, (3) considered (by the attending physician) to be able to tolerate a short period of spontaneous breathing (not having passed spontaneous breathing trial prior to study) and (4) awake.

The exclusion criteria were (1) age <18 years; (2) history of esophageal varices; (3) gastroesophageal surgery in the previous 12 months or gastroesophageal bleeding in the previous 30 days; (4) coagulation disorders (international normalized ratio $>1.5$ and activated partial thromboplastin time $>44$ seconds); (5) history of acute central or peripheral nervous system disorder or severe neuromuscular disease; (6) history of leukemia, severe chronic liver disease, solid organ transplantation, malignant tumor (because of their immunocompromised state and increased risk of infection); or (7) severe cardiac disease (to avoid provocation of hemodynamic instability).

\section{Measurements}

Patients were ventilated with a SERVO-i ventilator (Maquet, Solna, Sweden). A nasogastric feeding tube (NeuroVent Research, Toronto, ON, Canada) with electrodes to measure EAdi and balloons to measure esophageal pressure (Pes) and gastric pressure (Pga) were inserted through the nose. After verifying the correct positioning of the esophageal balloon by an occlusion test with spontaneous breaths [13], and after accurate positioning was confirmed by 
EAdi signals on a dedicated window on the SERVO-i ventilator (according to the manufacturer's recommendations), the nasogastric tube was secured. Flow and Paw measurements were acquired from the SERVO-i ventilator, and Pes and Pga levels were acquired via pressure transducers (NeuroVent Research).

Throughout the protocol, EAdi, Paw, flow, Pes and Pga waveforms were recorded by using a custom-made system (NeuroVent Research) for offline analysis. EAdi, Paw, flow and tidal volume $(\mathrm{Vt})$ were acquired from the SERVO-i ventilator via the RS232 serial port at a sampling rate of $100 \mathrm{~Hz}$. Pes and Pga were acquired at 2 $\mathrm{KHz}$ using via a DT $304 \mathrm{~A} / \mathrm{D}$ board (data translation) and synchronized to the RS232 serial port signals at 100 Hz. Ptp was calculated as Paw - Pes.

\section{Study protocol}

Patients were receiving intravenous analgesia with morphine at 1 to $2 \mathrm{mg} / \mathrm{hr}$, and no sedative was used during the experimental period. Patients were ventilated in pressure support mode (set by the attending physician) for 30 minutes after the nasogastric tube insertion. Patients were then switched to NAVA, with the NAVA level initially set to 0 for 3 minutes. Positive end-expiratory pressure (PEEP) and fraction of inspired oxygen $\left(\mathrm{FiO}_{2}\right)$ were set as prescribed by the attending physician. The NAVA level was then increased every 3 minutes in steps of $0.3 \mathrm{cmH}_{2} \mathrm{O} / \mu \mathrm{V}$ to a NAVA level of at least $3.0 \mathrm{cmH}_{2} \mathrm{O}$ / $\mu \mathrm{V}$. The upper pressure limit was set to $45 \mathrm{cmH}_{2} \mathrm{O}$ in order not to interfere with the titration. At each NAVA level, one non-assisted breath was obtained by reducing the NAVA level to 0 (hereafter NAVA zero breath). PEEP was unchanged during these breaths. At every NAVA level, one inspiratory occlusion was performed to measure neuromechanical efficiency (NME), as described below.

\section{Offline signal processing}

At each NAVA level, the last five breaths (prior to the NAVA zero breath) were analyzed. Figure 1 illustrates measurement points for signal processing. Neural inspiratory time $(\mathrm{Ti})$ was defined as the time between the onset of increasing EAdi and the point where EAdi dropped to $70 \%$ of its peak. Although EAdi ${ }_{p k}$ could be suggested as the end of $\mathrm{Ti}$, the EAdi drop to $70 \%$ of its peak was the off-cycling criterion for NAVA and thus allowed $\mathrm{Ti}$ to include detection of peak pressures and integration of inspiratory volume throughout the entire assist cycle (Figure 1). During each breath's Ti period, $\left.\mathrm{EAdi}_{\mathrm{pk}}\right)$ and peak airway pressure $\left(\mathrm{Paw}_{\mathrm{pk}}\right)$ were calculated. As well, $\Delta$ Pes and $\Delta$ Ptp between the onset of EAdi to their respective peak values were calculated. Note that the Pes signal has a negative trajectory and negative peak. Note also that peak values were obtained anytime during $\mathrm{Ti}$ and were not exactly matched in time.
Mean values for changes in EAdi and Pes were also calculated for each Ti period. Mean EAdi was obtained by integration during the Ti period and then divided by Ti. Mean Pes and Ptp were calculated the same way; however, values used during $\mathrm{Ti}$ integration were subtracted by the values measured at onset each of $\mathrm{Ti}$. The mean and peak values for EAdi, $\Delta$ Pes, Paw and $\Delta$ Ptp were closely related (range of $R^{2}=0.94$ to 0.97 ), and, for this reason, mean values are not reported. Of note, the mean values represented $60 \%$ to $70 \%$ of the peak values.

Breathing frequency $(\mathrm{Fb})$ was calculated on a breathby-breath basis as 60 divided by total breath time (that is, time between consecutive onsets of EAdi).

In order to quantify presence of paradoxical expiratory muscle relaxation during the neural inspiration, we calculated the change in Pga $\left(\triangle \mathrm{Pga}_{\text {paradox }}\right)$ between onset of EAdi and the lowest value observed during $\mathrm{Ti}$ for the assisted breath(s) preceding the non-assisted breath.

NME was calculated as $\mathrm{Paw}_{\mathrm{pk}} / \mathrm{EAdi}_{\mathrm{pk}}$ during inspiratory occlusions at each NAVA level [14]. This index provides information about inspiratory muscle contractility and whether NME could be affected by the protocol (for example, by dynamic hyperinflation).

\section{Main analysis}

PVBC was calculated as $\left(\mathrm{Vt}_{\text {insp }} / \mathrm{EAdi}_{\mathrm{pk}}\right)_{\text {no-assist }} /\left(\mathrm{Vt}_{\text {insp }} /\right.$ EAdi $\left._{\mathrm{pk}}\right)_{\text {assist. }}$ Another index, PVBC ${ }^{2}$, was calculated, simply by squaring PVBC [12]. Previous experimental work [12] showed that squaring PVBC was useful as a correction to improve its relationship to $\Delta \mathrm{Pes} / \Delta \mathrm{Ptp}$.

$\Delta \mathrm{Pes} / \Delta \mathrm{Ptp}$ (sign was reversed to obtain positive index value) was used as a direct index to quantify the patient inspiratory muscle effort $(\Delta \mathrm{Pes})$ contribution to total lung-distending pressure $(\Delta \mathrm{Ptp})$ during assisted breaths [12]. As the assist (Paw) increases, the patient's mechanical inspiratory effort ( $\triangle \mathrm{Pes}$ ) decreases (that is, becomes less negative), thus reducing its fraction relative to the total inspiratory effort $\Delta$ Ptp $(\mathrm{Ptp}=\mathrm{Paw}-\mathrm{Pes})$, indicating the relative contribution of patient inspiratory pressure and total inspiratory pressure.

In our previous study using the experimental animal model, both $P V B C$ and $P V B C^{2}$ were related to $\triangle \mathrm{Pes} / \triangle \mathrm{Ptp}$ [12] during increasing NAVA levels. In the animal study, respiratory drive (and its response) was fairly uniform. However, in non-sedated humans, intrabreath variability is often higher. In addition, we studied a heterogeneous group with a wide range of EAdi values at zero NAVA level. For this reason, we evaluated methods of refining the accuracy and stability of the PVBC and $\mathrm{PVBC}^{2}$ indices as described in the subsections below.

\section{Single versus averaged breaths}

We calculated the PVBC and $\mathrm{PVBC}^{2}$ indices in two ways: (1) using the same method described previously [12], 


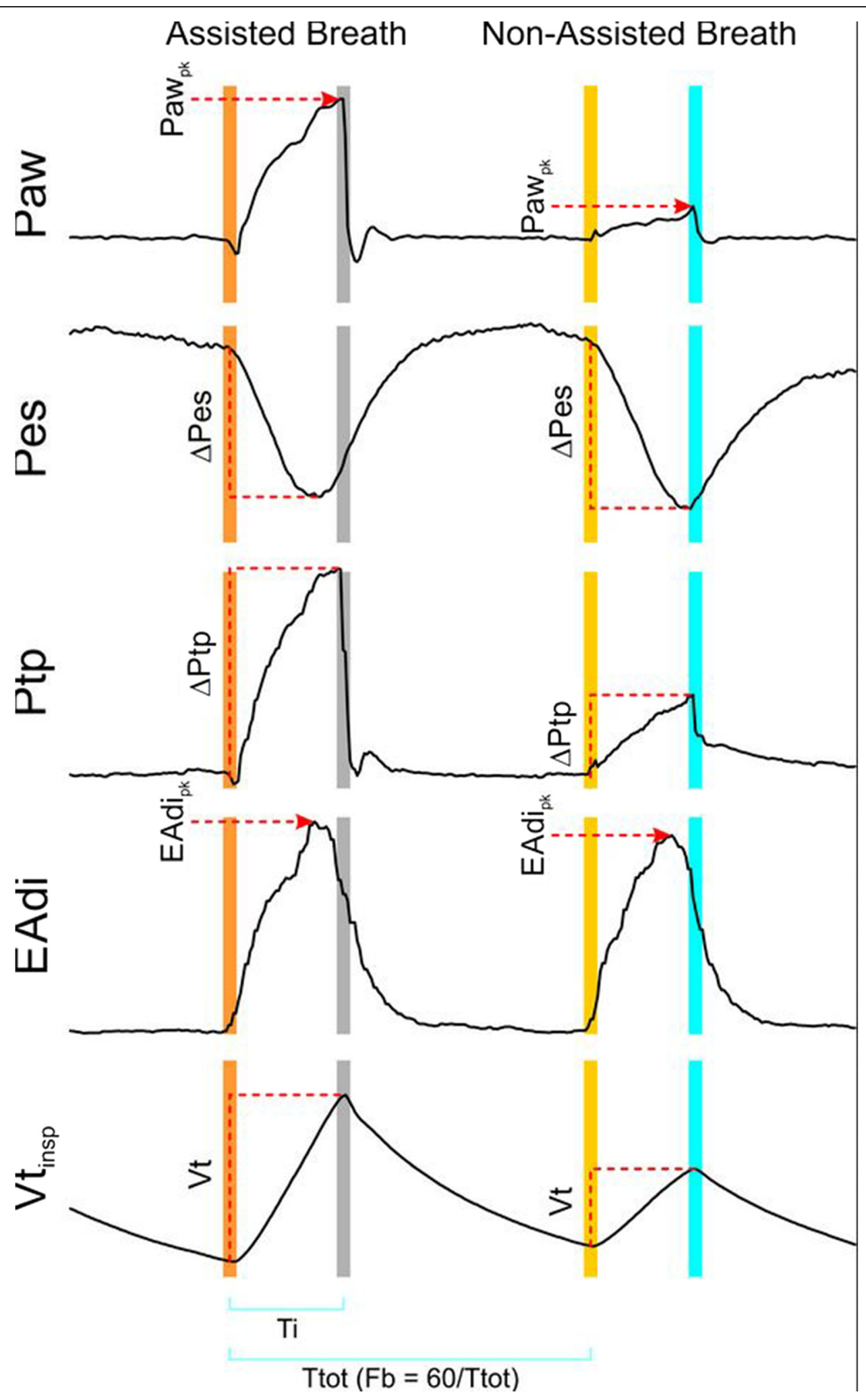

Figure 1 Description of reference points used for calculation of respiratory variables. Reference points are indicated for calculating peak airway pressure (Paw $\mathrm{wk}_{\mathrm{p}}$ ), change in esophageal pressure (Pes) from onset of electrical activity of the diaphragm (EAdi) to peak (nadir) ( $\Delta$ Pes), change in transpulmonary pressure (Ptp) from onset of EAdi to peak ( $\Delta$ Ptp), peak EAdi (EAdi $\left.p_{p k}\right)$ and inspiratory tidal volume $\left(V t_{\text {insp }}\right)$. Neural inspiratory period (Ti) and total breath time (Ttot) are indicated at bottom. Breathing frequency (Fb) was calculated as 60/Ttot. 
applying a single non-assisted breath (N1) compared with the previous single breath (referred to as ${ }^{\mathrm{N} 1} \mathrm{PVBC}$ and ${ }^{\mathrm{N} 1} \mathrm{PVBC}^{2}$ ); and (2) using $\mathrm{PVBC}$ and $\mathrm{PVBC}^{2}$ calculated with five averaged EAdi values from the five preceding breaths ("X5") (referred to as ${ }^{\mathrm{X}} \mathrm{PBVC}$ and ${ }^{\mathrm{X}} \mathrm{PBVC}^{2}$ ).

\section{Matching respiratory drive between assisted and non-assisted breaths}

Respiratory drive can be interpreted from both EAdi ${ }_{\mathrm{pk}}$ and $\mathrm{Ti}$. As mentioned in the Introduction above, to calculate the PVBC-related indices, we assumed that either respiratory drive should be fairly similar for the unassisted and the assisted breaths or breaths could be corrected by using respiratory drive to "normalize" $\mathrm{Vt} \mathrm{t}_{\text {insp }}$ [12]. To evaluate the effect of "matching" the respiratory drive for unassisted and assisted breaths on the relationship between PVBC and $\triangle \mathrm{Pes} / \triangle \mathrm{Ptp}$, we tested different criteria and/or filters. We calculated the ratio between $\mathrm{EAdi}_{\mathrm{pk}}$ with and without assist (EAdi $\mathrm{p}_{\mathrm{pk}, \text { no-assist }} / \mathrm{EAdi}_{\mathrm{pk} \text {,assist }}$ ) as well as $\mathrm{Ti}$ with and without assist $\left(\mathrm{Ti}_{\text {no-assist }} / \mathrm{Ti}_{\text {assist }}\right)$ at each NAVA level. Assuming that a ratio of 1 was a perfect match, we arbitrarily decided upon five ranges that successively reduced the degrees of freedom for either EAdi $_{\text {pk,no-assist }} / \mathrm{EAdi}_{\mathrm{pk} \text {,assist }}$ or $\mathrm{Ti}_{\text {no-assist }} / \mathrm{Ti}_{\text {assist }}: 0.63$ to $1.60,0.67$ to $1.50,0.71$ to $1.40,0.77$ to 1.30 and 0.83 to 1.20. Each range was selected to show the same relative changes above and below 1.0. We also tested if closely matched EAdi ${ }_{\mathrm{pk}}$ values between non-assisted and assisted breaths could eliminate the need for EAdi normalization in the PVBC indices. For this purpose, we calculated PVBC simply as the ratio between $\mathrm{Vt}_{\text {insp }}$ for non-assisted to assisted breaths ( $\mathrm{Vt}$ insp,no-assist $/ \mathrm{Vt}_{\text {insp,assist }}$ ), subsequently referred to as PVBC $\beta$ (using same annotations as the PVBC).

\section{Statistical analysis}

Statistical analysis was performed with SigmaPlot 12.5 (Systat Software, San Jose, CA, USA). Values in the text and figures are mean $\pm 95 \%$ confidence interval, unless otherwise indicated.

The relationship between different variables was tested with linear regression analysis. To identify the impact of averaging and breath matching on $R^{2}$-values for the PVBC- $\Delta$ Pes/ $\Delta$ Ptp relationship, one-way repeated-measures analysis of variance was performed. Post hoc comparison was performed by using the Student-Newman-Keuls test. A significant difference was defined as $P<0.05$. BlandAltman analysis was used to study agreement between methods.

\section{Results}

As shown in Table 1, 12 patients ( 3 males; age range, 38 to 82 years; predicted body weight range, 51 to $66.5 \mathrm{~kg}$ ) were studied ( 9 patients with pneumonia, 2 patients with cardiogenic pulmonary edema and 1 patient with acute respiratory distress syndrome). All patients were receiving supplemental oxygen $\left(\mathrm{FiO}_{2}=0.4\right.$ or 0.5$)$, with oxygen saturation ranging from $95 \%$ to $100 \%$.

All subjects reached a NAVA level of $3.0 \mathrm{cmH}_{2} \mathrm{O} / \mu \mathrm{V}$.

Group mean values for $\triangle \mathrm{Pga}_{\text {paradox }}$, the largest magnitude of paradoxical expiratory muscle relaxations during $\mathrm{Ti}$, were $-0.08(0.06)$ and $-0.08(0.05) \mathrm{cmH}_{2} \mathrm{O}$ during the single and five assisted breaths (preceding the nonassisted breaths), respectively.

Figure 2 exemplifies, in one patient, the effect of increasing NAVA level on $\mathrm{Paw}_{\mathrm{pk}}, \mathrm{EAdi}_{\mathrm{pk}}, \Delta \mathrm{Pes}$ and $\mathrm{Vt}_{\mathrm{insp}}$ (Figure 2A). It also provides examples of time tracings for Paw, EAdi, Vt and Pes for five assisted breaths and one unassisted breath (yellow vertical shadow) at one

Table 1 Patient descriptions ${ }^{a}$

\begin{tabular}{|c|c|c|c|c|c|c|c|c|}
\hline Patient & Age, yr & Sex & APACHE II score & Predicted weight, kg & Cause of respiratory failure & PEEP, $\mathrm{cmH}_{2} \mathrm{O}$ & $\mathrm{FiO}_{2}$ & $\mathrm{SpO}_{2}$ \\
\hline 1 & 58 & $\mathrm{~F}$ & 12 & 65 & Cardiogenic pulmonary edema & 8 & 0.4 & 95 \\
\hline 2 & 60 & $\mathrm{~F}$ & 22 & 65 & Cardiogenic pulmonary edema & 6 & 0.4 & 98 \\
\hline 3 & 32 & $\mathrm{~F}$ & 16 & 52 & Pneumonia & 8 & 0.4 & 95 \\
\hline 4 & 82 & M & 32 & 70 & ARDS, intestinal infection & 4 & 0.4 & 99 \\
\hline 5 & 72 & $\mathrm{~F}$ & 30 & 52 & Pneumonia & 5 & 0.4 & 98 \\
\hline 6 & 38 & M & 18 & 75 & Pneumonia & 8 & 0.5 & 95 \\
\hline 7 & 69 & $\mathrm{~F}$ & 24 & 60 & Pneumonia & 5 & 0.4 & 100 \\
\hline 8 & 81 & $\mathrm{~F}$ & 30 & 64 & Pneumonia & 7 & 0.4 & 98 \\
\hline 9 & 57 & $\mathrm{~F}$ & 20 & 50 & Pneumonia & 4 & 0.4 & 98 \\
\hline 10 & 76 & $\mathrm{~F}$ & 28 & 50 & Pneumonia & 5 & 0.4 & 100 \\
\hline 11 & 56 & M & 16 & 67 & Pneumonia & 5 & 0.4 & 100 \\
\hline 12 & 60 & $\mathrm{~F}$ & 28 & 58 & Pneumonia & 5 & 0.4 & 96 \\
\hline Mean (SD) & $61.8(15.6)$ & & $23.0(6.6)$ & $60.7(8.0)$ & & $5.8(1.5)$ & $0.41(0.02)$ & $98(2)$ \\
\hline
\end{tabular}

${ }^{\mathrm{a}} \mathrm{APACHE} \mathrm{II}$, Acute Physiology and Chronic Health Evaluation II; $\mathrm{FiO}_{2}$, Fraction of inspired oxygen; PEEP, Positive end-expiratory pressure; SD, Standard deviation; $\mathrm{SpO}_{2}$, Pulse oxygen saturation. 


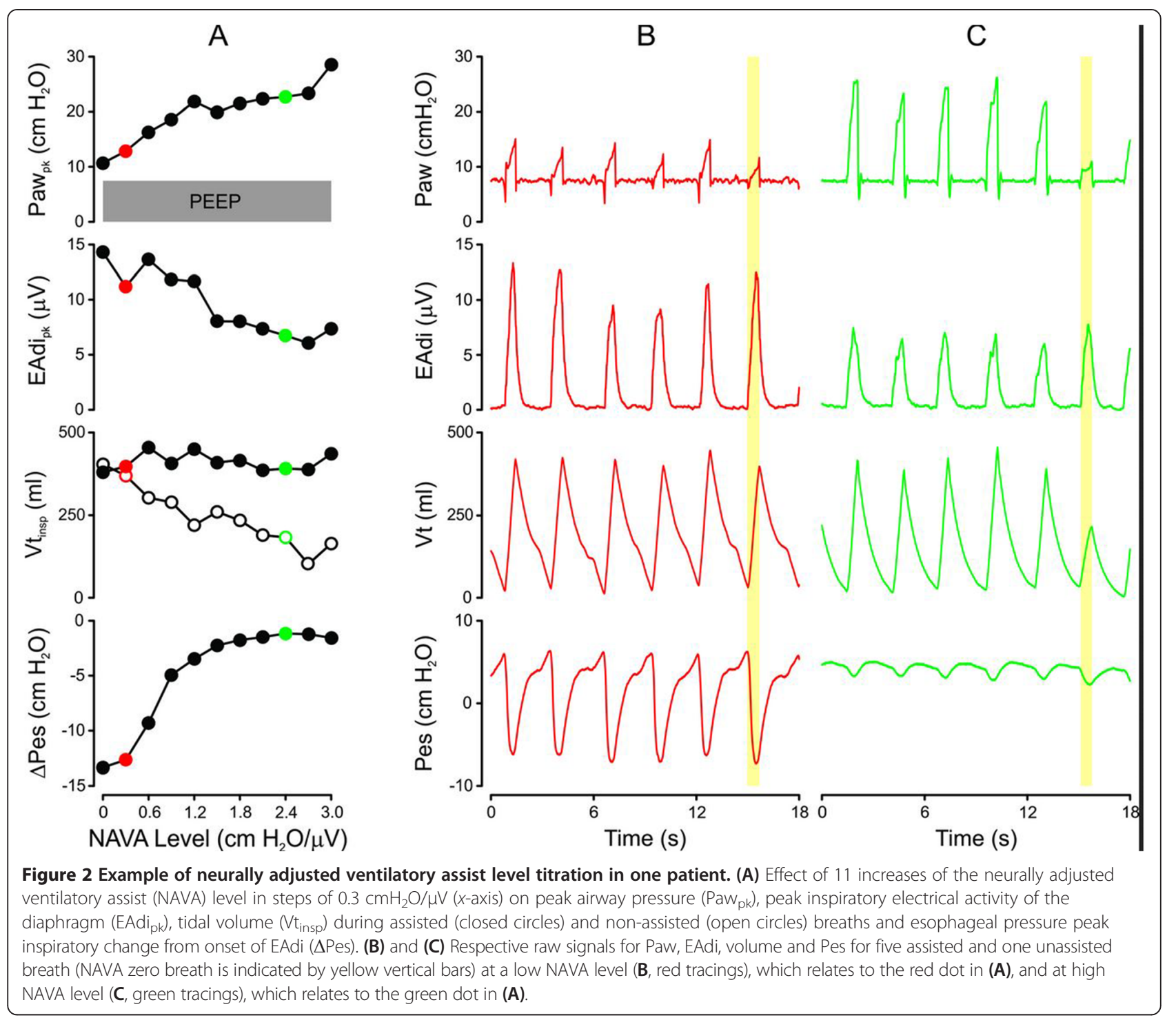

low and one high NAVA level (Figure 2B and C) out of the total of eleven applied.

The NME did not change significantly from NAVA level zero $\left(\mathrm{NME}=1.40 \pm 0.63 \mathrm{cmH}_{2} \mathrm{O} / \mu \mathrm{V}\right)$ to the last titration step at NAVA level $3.0 \mathrm{~cm} \mathrm{H}_{2} \mathrm{O} / \mu \mathrm{V}(\mathrm{NME}=1.70 \pm 0.86$ $\left.\mathrm{cmH}_{2} \mathrm{O} / \mu \mathrm{V}\right)$.

Figure 3 shows how averaging five assisted breaths (closed symbols, "X5" notation) versus using one nonassisted breath (open symbols, "N1" notation) prior to the non-assisted breath influences the PVBC indices' correlation to $\Delta \mathrm{Pes} / \Delta \mathrm{Ptp}$. It also shows the impact of respiratory drive "matching" for both EAdi $_{\text {pk,no-assist }}$ / EAdi $_{\text {pk,assist }}$ (orange symbols) and $\mathrm{Ti}_{\text {no-assist }} / \mathrm{Ti}_{\text {assist }}$ (blue symbols) on the determination coefficients $\left(R^{2}, y\right.$-axes) between PVBC indices and $\triangle$ Pes $/ \triangle$ Ptp. PVBC versus $\Delta$ Pes/ $\Delta$ Ptp showed higher determination coefficients $(y$-axes) when calculated from the average of five preceding assisted breaths compared with when they were calculated with one assisted breath. Better matching of $\mathrm{EAdi}_{\mathrm{pk} \text {,no-assist }} / \mathrm{EAdi}_{\mathrm{pk} \text {,assist }}$ increased determination coefficients for PVBC indices with five breaths average, reaching significance with matching criteria (EAdi $i_{\mathrm{pk}, \text { no-assist }} /$ EAdi $\left._{\text {pk,assist }}\right)$ at 0.77 to 1.30 .

Improved matching of $\mathrm{Ti}$ ( $x$-axes in Figure 3 ) did not improve determination coefficients $(y$-axes in Figure 3$)$ between PVBC indices and $\triangle \mathrm{Pes} / \triangle \mathrm{Ptp}$. We found that the $\mathrm{EAdi}_{\mathrm{pk}, \text { no-assist }} / \mathrm{EAdi}_{\mathrm{pk} \text {,assist }}$ of 0.77 to 1.30 provided the best combination of highest $R^{2}$ values, lowest variability and least exclusion of data points not meeting matching criteria. In summary, this analysis showed the highest determination coefficients between the PVBC indices and $\Delta \mathrm{Pes} / \Delta \mathrm{Ptp}$ when the PVBC was calculated using an average of five assisted breaths with $\mathrm{EAdi}_{\mathrm{pk} \text {,no-assist }} / \mathrm{EAdi}_{\mathrm{pk} \text {,assist }}$ within the 0.77 to 1.30 range. The distribution of 


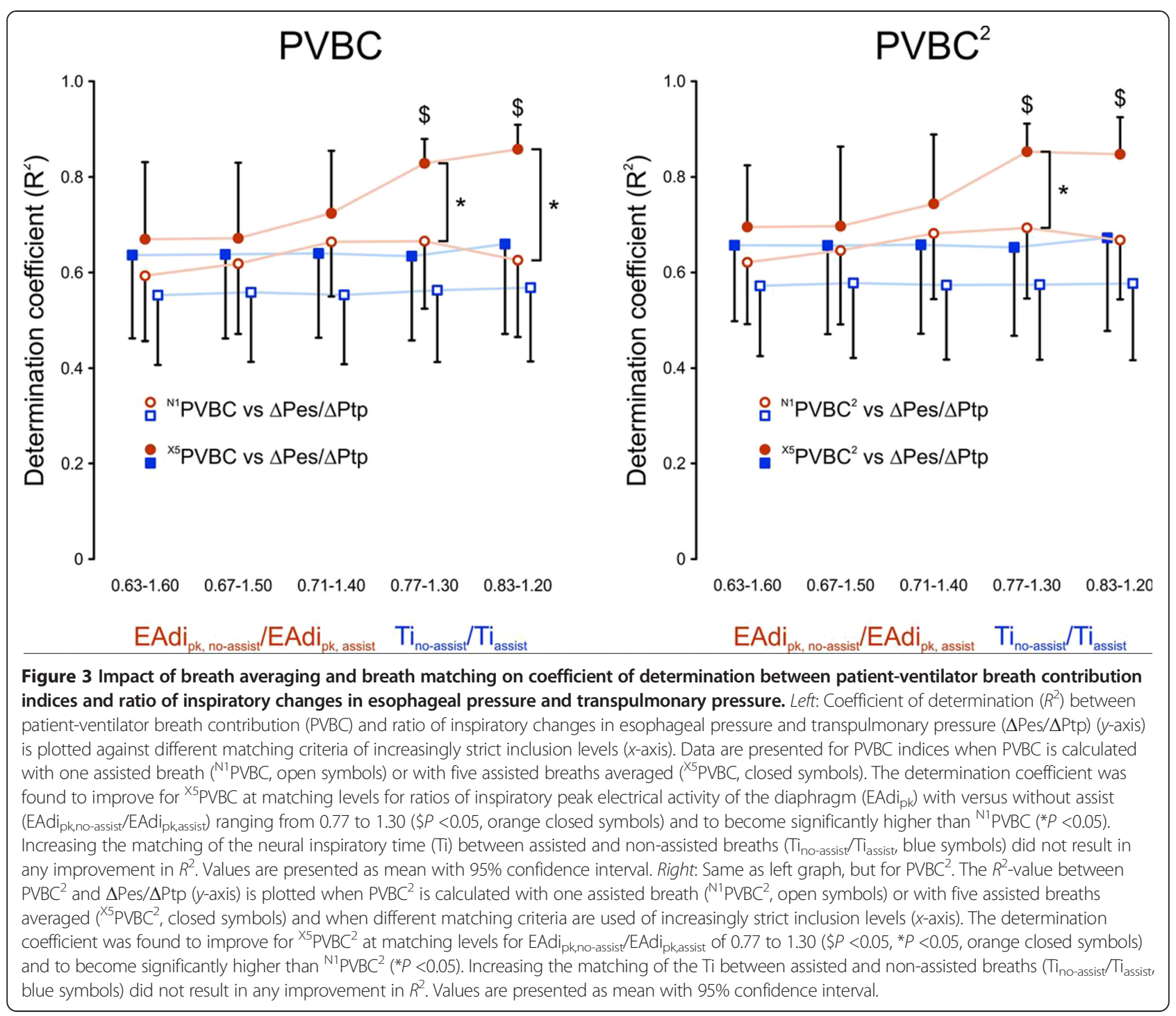

EAdi $_{\text {pk,no-assist }} /$ EAdi $_{\text {pk,assist }}$ for all patients and NAVA levels is presented in Figure 4.

Henceforth, results are reported only for patients with EAdi $_{\text {pk,no-assist }} / \mathrm{EAdi}_{\mathrm{pk} \text {,assist }}$ ratios between 0.77 and 1.30 .

Figure 5 shows group mean values for $\triangle \mathrm{Pes}, \mathrm{Paw}_{\mathrm{pk}}$ (including PEEP), $\triangle$ Ptp (including PEEP), PEEP, EAdi ${ }_{\mathrm{pk}}$, $\mathrm{Vt}_{\text {insp }}$, and $\mathrm{Fb}$ for increasing NAVA levels. With progressive increases in NAVA level, there was a concomitant reduction in $\mathrm{EAdi}_{\mathrm{pk}}$ until a point where the increase in $\mathrm{Vt}$ plateaued. $\mathrm{Fb}$ did not change for the titration of NAVA levels.

Figure 6A illustrates the group mean values for ${ }^{\mathrm{X}} \mathrm{PVBC},{ }^{\mathrm{X} 5} \mathrm{PVBC}^{2}$ and $\triangle \mathrm{Pes} / \Delta \mathrm{Ptp}$ with increasing NAVA levels. Figures $6 B$ and $C$ show $\Delta$ Pes $/ \Delta P$ tp $(x$-axes) plotted against ${ }^{\mathrm{X} 5} \mathrm{PVBC}$ and ${ }^{\mathrm{X} 5} \mathrm{PVBC}^{2}$ ( $y$-axes), respectively. Figure 6D shows the same information as Figure 6A, but with PVBC calculated without normalizing $\mathrm{Vt}_{\text {insp }}$ by EAdi $_{\mathrm{pk}}$ (referred to as ${ }^{\mathrm{X}} \mathrm{PVBC} \beta$ and ${ }^{\mathrm{X} 5} \mathrm{PVBC} \beta^{2}$ ). The proportionality between ${ }^{\mathrm{X} 5} \mathrm{PVBC} \beta$ versus $\Delta \mathrm{Pes} / \Delta \mathrm{Ptp}$ as well as ${ }^{\mathrm{X}} \mathrm{PVBC} \beta^{2}$ versus $\Delta \mathrm{Pes} / \Delta \mathrm{Ptp}$ is demonstrated in Figure $6 \mathrm{E}$ and $\mathrm{F}$.

As the NAVA level increased, ${ }^{\mathrm{X} 5} \mathrm{PVBC}$ and ${ }^{\mathrm{X}}{ }_{\mathrm{PVBC}}{ }^{2}$ as well as ${ }^{\mathrm{X}} \mathrm{PVBC} \beta$ and ${ }^{\mathrm{X}} \mathrm{PVBC}^{2}$ (panels $\mathrm{A}$ and $\mathrm{D}$ ) decreased in a fashion similar to that of $\Delta \mathrm{Pes} / \Delta \mathrm{Ptp}$, showing less contribution by the patient. Squaring the indices significantly adjusted the regression coefficients and moved the intercepts for ${ }^{\mathrm{X}} \mathrm{PVBC}^{2}$ (panel $\mathrm{C}$ ) and ${ }^{\mathrm{X}} \mathrm{PVBC}^{2}$ (panel F) closer to zero.

Table 2 shows group mean values for bias, standard deviation, lower and upper levels of agreement and precision of the Bland and Altman analysis for ${ }^{\mathrm{X} 5} \mathrm{PVBC}$, ${ }^{\mathrm{X}} \mathrm{PVBC}^{2},{ }^{\mathrm{X}} \mathrm{PVBC} \beta$ and ${ }^{\mathrm{X}}{ }^{\mathrm{PVBC}} \beta^{2}$ indices versus $\triangle \mathrm{Pes} /$ $\triangle \mathrm{Ptp}$. Squared indices, ${ }^{\mathrm{X}} \mathrm{PVBC} \mathrm{C}^{2}$ and ${ }^{\mathrm{X}}{ }^{\mathrm{PVBC}} \beta^{2}$, reduced bias $(\mathrm{P}<0.05)$, and better agreement for lower $(\mathrm{P}<0.05)$ and upper $(\mathrm{P}<0.05)$ levels of adjustment with regards to $\Delta$ Pes/ $\Delta$ Ptp. All data in Figure 6 and Table 2 use the 

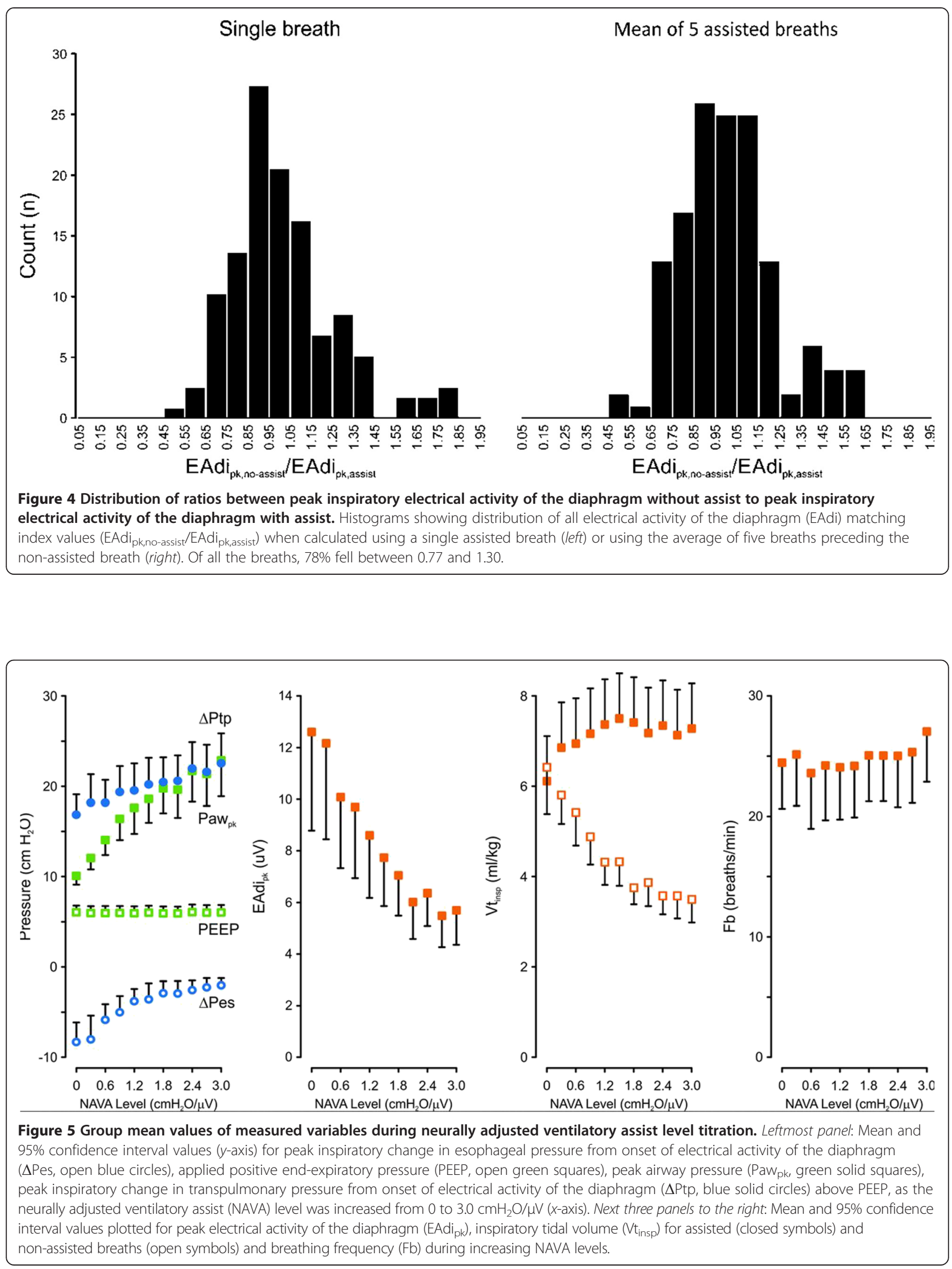


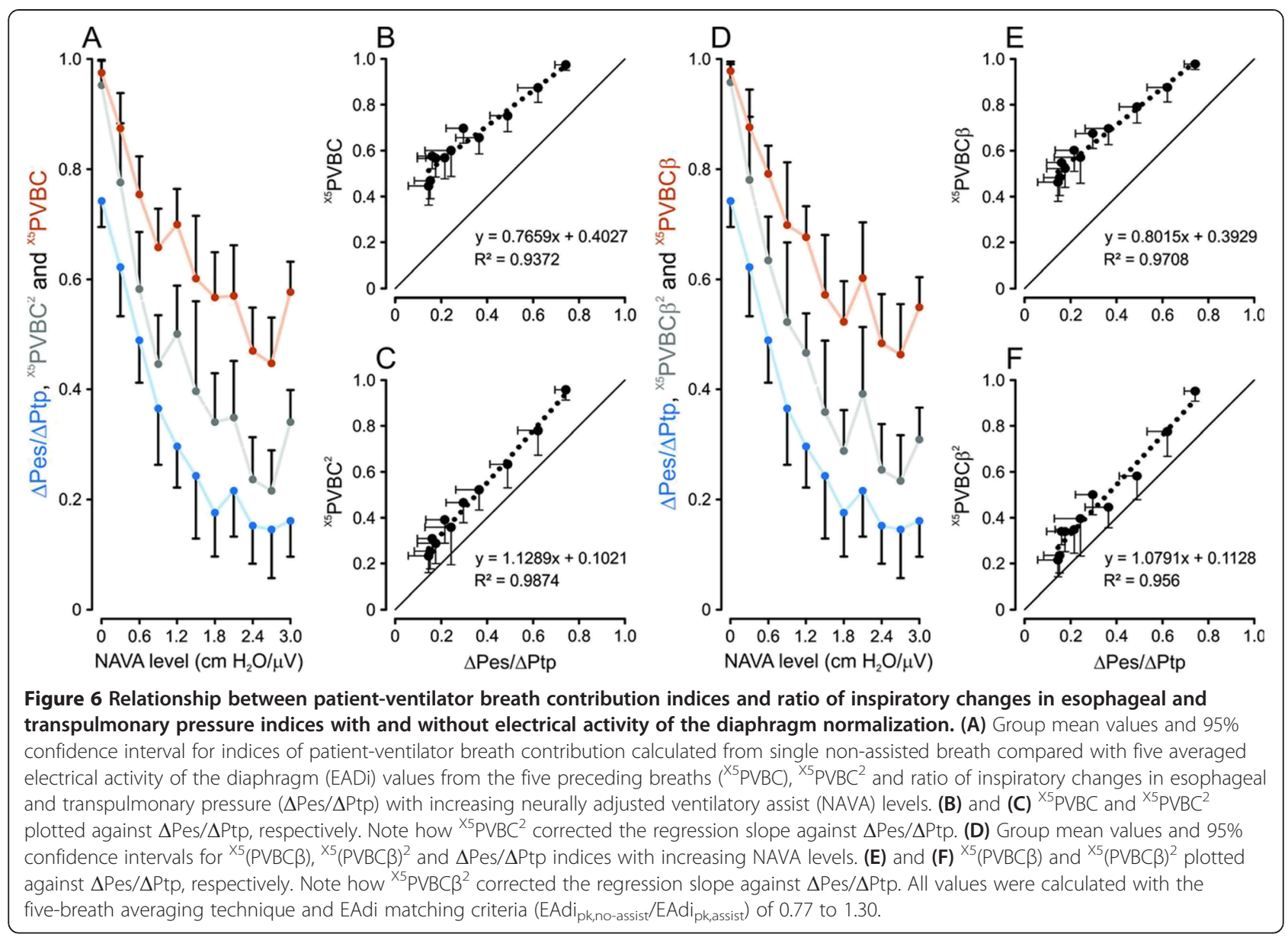

EAdi $_{\mathrm{pk}}$ ratio inclusion criteria of $0.77-1.30$ between single non-assisted breath and mean of previous 5 breaths.

\section{Discussion}

The results of the present study validate a clinical index that can be used to quantify the relative inspiratory effort of a patient during assisted ventilation. Comparison of $\mathrm{Vt}_{\text {insp }}$ corrected for neural inspiratory drive for a nonassisted breath $\left(\mathrm{Vt}_{\mathrm{insp}} / \mathrm{EAdi}_{\mathrm{pk}}\right)_{\text {no-assist }}$ to that during an assisted breath (that is, $\left.\left(\mathrm{Vt}_{\mathrm{insp}} / \mathrm{EAdi}_{\mathrm{pk}}\right)_{\mathrm{assist}}\right)$ resulted in a
PVBC index that closely reflected the ratio between patient $(\Delta \mathrm{Pes})$ and total (patient + ventilator $=\Delta \mathrm{Ptp})$ mechanical inspiratory effort. We also demonstrate that selection of non-assisted and assisted breaths with wellmatched neural efforts improved the reliability of the PVBC index. Computation using an average of the five preceding assisted breaths, squaring PVBC and including only breaths with EAdi ratios for non-assisted and assisted breaths between 0.8 and 1.3 resulted in the most reliable PVBC $\left({ }^{\mathrm{X} 5} \mathrm{PVBC}^{2}\right)$ index. Using EAdi to match

Table 2 Bland-Altman analysis for ${ }^{\mathrm{X}} \mathrm{PVBC},{ }^{\mathrm{X}} \mathrm{PVBC}{ }^{2},{ }^{\mathrm{X}} \mathrm{PVBC} \beta$ and ${ }^{\mathrm{X}} \mathrm{PVBC} \beta^{2}$ with reference to $\Delta \mathrm{Pes} / \Delta \mathrm{Ptp}{ }^{\mathrm{a}}$

\begin{tabular}{|c|c|c|c|c|c|c|c|c|}
\hline & ${ }^{\mathrm{X} 5} \mathrm{PVBC}$ & & ${ }^{X 5} \mathrm{PVBC}$ & & ${ }^{X 5}$ PVBC & & ${ }^{\mathrm{X} 5} \mathrm{PVBC}$ & \\
\hline & Mean & $95 \% \mathrm{Cl}$ & Mean & $95 \% \mathrm{Cl}$ & Mean & $95 \% \mathrm{Cl}$ & Mean & $95 \% \mathrm{Cl}$ \\
\hline Bias & 0.34 & 0.05 & $0.16^{*}$ & 0.06 & 0.33 & 0.05 & $0.16^{*}$ & 0.06 \\
\hline SD & 0.10 & 0.01 & 0.10 & 0.02 & 0.09 & 0.02 & 0.08 & 0.02 \\
\hline Lower LoA & 0.16 & 0.07 & $-0.04^{*}$ & 0.09 & 0.16 & 0.07 & $-0.01^{*}$ & 0.08 \\
\hline Upper LoA & 0.56 & 0.07 & $0.35^{*}$ & 0.04 & 0.50 & 0.06 & $0.32^{*}$ & 0.06 \\
\hline Precision & 0.40 & 0.06 & 0.39 & 0.07 & 0.34 & 0.07 & 0.33 & 0.08 \\
\hline
\end{tabular}

${ }^{a} \mathrm{Cl}$, Confidence interval; LoA, Level of adjustment; $\triangle \mathrm{Pes} / \triangle \mathrm{Ptp}$, Ratio of inspiratory changes in esophageal and transpulmonary pressure; PVBC $\beta$, Patient-ventilator breath contribution as ratio of inspiratory tidal volume for non-assisted to assisted breaths; ${ }^{X} \mathrm{PBVC}$, Patient-ventilator breath contribution calculated from single non-assisted breath compared with five averaged electrical activity of the diaphragm values from the five preceding breaths; SD, Standard deviation. ${ }^{*} P<0.05$ versus ${ }^{\mathrm{X}} \mathrm{PVBC}$ and ${ }^{\mathrm{X}} \mathrm{PVBC} \beta$. 
non-assisted and assisted breaths eliminated the need to correct for changes in neural respiratory drive and allowed computation of PVBC based on inspiratory volume alone.

The results of our clinical study of patients with ARF generally confirm those of the previous study in animals by Grasselli et al. [12]. We found that the coefficient of determination $\left(R^{2}\right)$ between PVBC indices and $\Delta$ Pes $/ \Delta$ Ptp improved when neural inspiratory drive was matched between assisted and non-assisted breaths. Neural drive can be considered to have two major components: (1) neural breathing frequency (that is, the periodic repetition of neural activation, which is a temporal indicator of neural respiratory drive) and (2) amplitude (that is, the magnitude of neural respiratory drive). Our finding that matching assisted and non-assisted breaths for $\mathrm{Ti}$ had little effect on $R^{2}$ between PVBC and $\Delta$ Pes/ $\Delta$ Ptp suggests that temporal variability in neural drive had little influence on the accuracy of the PVBC index. However, EAdi $\mathrm{pk}_{\mathrm{p}}$ had a strong impact in improving the fit between PVBC and $\Delta \mathrm{Pes} / \Delta \mathrm{Ptp}$, suggesting that the magnitude of neural inspiratory effort is important for the accuracy of the PVBC index.

Transesophageal measurements of EAdi mainly represent motor unit activation for a portion of the crural diaphragm. Despite this, studies have demonstrated that the EAdi provides a good measure of the global diaphragm activation in healthy subjects [15] and mechanically ventilated patients with ARF [16]. Nonetheless, changes in respiratory muscle recruitment may cause alterations of chest wall configuration that would change NME between assisted and non-assisted breaths [15-17]. In the present study, the NME obtained during the occlusions was not affected by increasing NAVA levels.

The present study demonstrates a better fit to the regression line (higher $R^{2}$ values) between $\mathrm{PVBC}$ and $\Delta \mathrm{Pes} / \Delta \mathrm{Ptp}$ when an average of five assisted breaths was used compared with a single breath. We did not apply this approach for the non-assisted breaths because of clinical concerns about removing the assist for several breaths and the potential of altering respiratory muscle recruitment for the various breaths.

Grasselli et al. [12] showed that squaring PVBC values linearized the regression slope obtained with $\Delta \mathrm{Pes} / \Delta \mathrm{Ptp}$ with changes in NAVA levels, and it also moved the intercept closer to zero. Our findings were similar, although they were not as evident. Squaring ${ }^{\mathrm{X}} \mathrm{PVBC}$ altered the regression slope and moved the intercept closer to zero compared with ${ }^{\mathrm{X} 5 \mathrm{PVBC}}$; however, there was no group mean increase of improved fit to the regression line between PVBC and $\triangle \mathrm{Pes} / \triangle \mathrm{Ptp}$ as would be expected if curvilinearity had been removed. Yet again, this could be due to the wide heterogeneity in physiological and pathological factors between patients.
Our finding that a ratio of EAdi between assisted and non-assisted breaths of 0.78 to 1.30 produced equally good fit to $\triangle \mathrm{Pes} / \triangle \mathrm{Ptp}$ when we calculated ${ }^{\mathrm{X}} \mathrm{PVBC} \beta^{2}$ from "only" the ratio of $\mathrm{Vt}_{\text {insp }}$ from unassisted to assisted breaths (that is, without normalizing to EAdi) confirms our initial hypothesis that when inspiratory effort is matched between assisted and non-assisted breaths, $\mathrm{Vt}_{\text {insp }}$ must change if synchronized assist is added or removed. Hence, the ratio of $\mathrm{Vt}_{\text {insp }}$ values for non-assisted and assisted breaths should be close to a value of 1 when no assist is being provided (the patient generates all the volume) and near zero when a breath is fully assumed by the ventilator.

\section{Critique of methods}

The results given in the present study relate to peak values (that is, changes in amplitude in the signal between the onset of EAdi and the peak of a signal). Regarding Paw, one could argue that because NAVA does not have a plateau pressure, peak and mean values would provide different information. Regression analysis indicated extremely high correlation between the peak and mean values for Paw. Similarly, other variables, such as $\Delta$ Pes, $\Delta$ Ptp and $E_{\text {Adi }}$, showed extremely strong relationships to their respective mean values. Given that pressures and EAdi are presented as peak values on the ventilator, we preferred to present results that had the closest relationship to clinical implementation.

In spontaneously breathing patients recovering from acute respiratory failure, expiratory muscle contraction during expiration followed by expiratory muscle relaxation during the ensuing inspiration may invalidate and amplify the decrease in esophageal pressure [18]. Such an overestimation of $\Delta$ Pes can be detected by an endexpiratory decrease in Pga causing a concomitant decrease in Pes that is not related to inspiratory muscle effort [19]. In the present study, we used onset of EAdi as the starting point to calculate $\Delta \mathrm{Pes}$, which ensured that diaphragm contraction had started and eliminated the possibility for preinspiratory overestimation of the $\Delta$ Pes. Our quantification of paradoxical expiratory muscle relaxation during neural inspiration as $\Delta \mathrm{Pga}_{\text {paradox }}$, calculated as the change in Pga between onset of EAdi and the lowest value observed during $\mathrm{Ti}$ for the assisted breath(s) preceding the non-assisted breath, was miniscule. The latter shows that end-expiratory expiratory muscle relaxation was not an important contributor to our results.

As depicted in Figure 6, both ${ }^{\mathrm{X} 5} \mathrm{PVBC}^{2}$ and ${ }^{\mathrm{X} 5} \mathrm{PVBC} \beta^{2}$ showed values about 0.1 relative units higher than $\triangle \mathrm{Pes} /$ $\triangle$ Ptp. One reason for higher PVBC indices was that $\triangle$ Pes decreases more than EAdi during assisted breaths. In fact, EAdi $_{\mathrm{pk}}$ does not reach zero when $\triangle$ Pes indicates $100 \%$ unloading [20]. This means that for a given EAdi ${ }_{\mathrm{pk}}$, 
non-assisted breaths can generate more $\mathrm{Vt}_{\text {insp }}$ than during assisted breaths [12]. Moreover, at a NAVA level of zero, the assist is not a true "zero assist," because the SERVO-i ventilator still delivers a pressure of $2 \mathrm{cmH}_{2} \mathrm{O}$. These factors would act to shift PVBC indices upward.

Relaxation of the chest wall or expiratory muscle recruitment prior to EAdi off-cycling opens the expiratory valve during assisted breaths. This is due to the increase in $\mathrm{Paw}_{\mathrm{pk}}$ by $3 \mathrm{cmH}_{2} \mathrm{O}$ above target, causing a pressure off-cycling algorithm to be activated. If this happens, the $\mathrm{Paw}_{\mathrm{pk}}$ is somewhat $\left(3 \mathrm{cmH}_{2} \mathrm{O}\right)$ higher than expected and the $\Delta \mathrm{Pes} / \Delta \mathrm{Ptp}$ ratio would be lower than expected, especially at the lowest NAVA levels. Another reason that the $\Delta$ Pes/ $\Delta$ Ptp ratio was less than 1.0 at the lowest NAVA level could be that Paw was lost because the endotracheal tube resistance led to overestimation of the Paw used to calculate Ptp.

Our finding of a $16 \%$ bias with the Bland-Altman analysis probably relates to a combination of overestimating PVBC as well as underestimating $\triangle \mathrm{Pes} / \Delta \mathrm{Ptp}$.

A limitation of this study's design is that we did only one "PVBC maneuver" (NAVA zero breath) per NAVA level. Consequently, if the breath without assist failed to meet the inclusion criteria for EAdi ${ }_{\mathrm{pk}}$ or Ti matching, we would lose the PVBC calculation for that NAVA level. If applied as an automatic function for use in the clinic, the non-assisted breaths could be repeated intermittently to increase the likelihood of obtaining acceptable and reproducible PVBC values.

Breathing patterns are affected by many factors, and stable activation and rhythm require a low level of disturbance. The protocol of the present study was performed by manual interventions by the investigators at the bedside, which could have distracted the patients compared with a system with built-in algorithms for non-assisted breaths and occlusions.

Three minutes at each NAVA level could be considered short; however, our data indicate that this was sufficient to produce clear reductions in both $\triangle$ Pes and EAdi $_{\text {pk }}$ for each NAVA level. Viale and colleagues showed that about five breaths were sufficient for patients to adapt and adjust to the new assist level during pressure support ventilation [21]. In the present study, we therefore focused on relatively quick unloading rather than on the effects of $\mathrm{CO}_{2}$ and $\mathrm{pH}$ on respiratory drive. To the contrary, our data showing that $78 \%$ of the breaths fell within the 0.77 to 1.30 matching criteria (one breath to the next) strongly suggest that the first unassisted breath is affected little by removal of ventilatory assist.

\section{Clinical relevance}

In previous clinical studies, researchers have reported, on average, EAdi $\mathrm{pk}_{\mathrm{pk}}$ values of about $10 \mu \mathrm{V}$ when the
NAVA level was adjusted to match $\mathrm{Paw}_{\mathrm{pk}}$ during pressure support, providing clinically acceptable Vt levels $[5,22,23]$. (Note that although the absolute value of EAdi can be influenced by anatomical differences, this average value is representative of published data obtained from over 560 patients.) According to the results of the present study, this corresponds to average ${ }^{\mathrm{X} 5} \mathrm{PVBC}^{2}$ and ${ }^{\mathrm{X}} \mathrm{PVBC}^{2}$ indices of about 0.5 (that is, indicating the patient's contribution is about half the total effort). It is interesting to observe that at an EAdi of $10 \mu \mathrm{V}$, the $\Delta$ Pes was about $-5 \mathrm{cmH}_{2} \mathrm{O}$, which could be considered a normal workload. As demonstrated previously during synchronized assist with NAVA, breathing frequency provided little information about acute changes in respiratory load and drive. As depicted in Figure 5, the initial increase in Paw and $\triangle$ Ptp decreased at NAVA levels of 1.5 to 1.8. It has been hypothesized that the onset of this plateau indicates that the patient is "satisfied" by the assist [24]. In the present study, this occurred at an average EAdi of 7 to $8 \mu \mathrm{V}$, with ${ }^{\mathrm{X}}{ }^{\mathrm{PVBC}}{ }^{2}$ and ${ }^{\mathrm{X}}{ }^{\mathrm{PVBC}} \beta^{2}$ indices of about 0.3 to 0.4 (that is, when the patient's contribution was about one-third of total effort). Although the highest precision of 0.3 (Bland-Altman analysis) obtained with ${ }^{\mathrm{X}}{ }^{\mathrm{PVBC}} \beta^{2}$ could be considered somewhat low, targeting ${ }^{\mathrm{X}} \mathrm{PVBC} \beta^{2}$ of 0.5 while monitoring EAdi with a target $10 \mu \mathrm{V}$ would likely improve the ability to control patient unloading. This type of monitoring would have a direct impact on how to set the ventilator's assist and, perhaps more important, would provide clinical studies aimed at ensuring avoidance of overassist and optimizing assist for faster weaning. In the present study, PVBC analysis was done by neurally synchronized and proportional assist. Principally, the comparison of $\mathrm{Vt}_{\text {insp }}$ for assisted and nonassisted breaths of similar EAdi amplitude should also work with pressure support ventilation; however, future studies are required.

\section{Conclusions}

The present study demonstrates a clinical index used to quantify the relative inspiratory effort of a patient during assisted ventilation. Computation of PVBC as a ratio of $\mathrm{Vt}$ values from one non-assisted breath to the average of five preceding assisted breaths, squaring PVBC and including only breaths with $\mathrm{EAdi}_{\mathrm{pk}}$ whose ratio between non-assisted and assisted breaths is within the range of 0.77 to 1.30 results in a clinically useful PVBC index.

\section{Key messages}

- The ratio of inspired tidal volume $\left(\mathrm{Vt}_{\mathrm{insp}}\right)$ and inspiratory peak electrical activity of the diaphragm $\left(E A_{i j}{ }_{p k}\right)$ between non-assisted and assisted breaths, defined as patient and ventilator breath 
contributions (PVBCs), can be used to predict the relative contribution of the inspiratory muscles versus that of the ventilator during neurally adjusted ventilatory assist (NAVA).

- Computation of PVBC as a ratio of tidal volumes from one non-assisted breath to the average of five preceding assisted breaths, squaring PVBC and including only breaths with EAdi ${ }_{p k}$ whose ratio between non-assisted and assisted breaths is within the range of 0.77 to 1.30 resulted in a clinically useful PVBC index.

\section{Abbreviations}

APACHE II: Acute Physiology and Chronic Health Evaluation II, ARF, Acute respiratory failure; Cl: Confidence interval; EAdi: Electrical activity of the diaphragm; EAdi pk: Peak inspiratory electrical activity of the diaphragm; $\mathrm{Fb}$ : Breathing frequency; $\mathrm{FiO}_{2}$ : Fraction of inspired oxygen; ICU: Intensive care

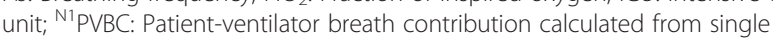
non-assisted breath compared with the previous single breath; NAVA: Neurally adjusted ventilatory assist; NME: Neuromechanical efficiency; Paw: Airway pressure; Paw pk: Peak airway pressure; PEEP: Positive endexpiratory pressure; Pes: Esophageal pressure; $\Delta$ Pes: Peak inspiratory change in esophageal pressure from onset of electrical activity of the diaphragm; Pga: Gastric pressure; Ptp: Transpulmonary pressure; $\triangle$ Ptp: Peak inspiratory change in transpulmonary pressure from onset of electrical activity of the diaphragm; PVBC: Patient-ventilator breath contribution; SD: Standard deviation; $\mathrm{SpO}_{2}$ : Pulse oxygen saturation; Ti: Neural inspiratory period; Ttot: Total breath time; $V_{t_{\text {insp: }}}$ Inspired tidal volume; ${ }^{\times 5}$ PBVC: Patient-ventilator breath contribution calculated from single non-assisted breath compared with five averaged electrical activity of the diaphragm values from the five preceding breaths.

\section{Competing interests}

$\mathrm{JB}$ and CS have made inventions related to neural control of mechanical ventilation that are patented. The patents are assigned to the academic institution(s) where the inventions were made. The license for these patents belongs to Maquet Critical Care. Future commercial uses of this technology may provide financial benefit to JB and CS through royalties. JB and CS each own $50 \%$ of NeuroVent Research (NVR). NVR is a research and development company that builds the equipment and catheters for research studies. NVR has a consulting agreement with Maquet Critical Care. AS is a paid consultant to Maquet Critical Care. The remaining authors declare that they have no competing interests.

\section{Authors' contributions}

LL was responsible for the conception and design of the study; acquisition, analysis and interpretation of data; and drafting and revising the manuscript for final approval of the version to be published. SL was responsible for the design of study, acquisition and analysis of data, and revising the manuscript. JX was responsible for acquisition and analysis of data and revising the manuscript. YY was participated in the design of the study, acquisition and analysis of data, and revising the manuscript. AS was involved with the conception and design of the study, interpretation of the data, revising the manuscript for important intellectual content, and final approval of the version to be published. JB was involved with the conception and design of the study, analysis and interpretation of data, drafting and revising the manuscript for important intellectual content, and final approval of the version to be published. CS was responsible for the conception and design of the study, analysis and interpretation of data, drafting and revising the manuscript for important intellectual content, and final approval of the version to be published. HQ was responsible for the conception and design of study, analysis and interpretation of the data, drafting and revising the manuscript for important intellectual content, and final approval of the version to be published. All authors read and approved the final manuscript.

\section{Acknowledgements}

This study was supported by the Natural Science Foundation of Jiangsu Province (Project BK20131302), the Foundation of the National Key Clinical Department of Critical Care Medicine (2010), the Ministry of Health of the People's Republic of China (Special Fund for Health-Scientific Research in the Public Interest Program 201202011) and the Clinical Science and Technology Specific Projects of Jiangsu Province (BL2013030). CS was supported by the RS McLaughlin Foundation. We are indebted to Norman Comtois for technical assistance and assistance with data analysis.

\section{Author details}

'Department of Critical Care Medicine, Zhongda Hospital, Southeast University, School of Medicine, 87 Dingjiaqiao Street, Nanjing 210009, China. ${ }^{2}$ Keenan Research Centre for Biomedical Science and Department of Critical Care, St Michael's Hospital, 30 Bond Street, Toronto, ON M5B1W8, Canada. ${ }^{3}$ Department of Medicine and Interdepartmental Division of Critical Care Medicine, University of Toronto, Suit RFE3-805, 200 Elizabeth Street, Toronto, ON M5G 2C4, Canada. ${ }^{4}$ Department of Pediatrics, University of Toronto, 555 University Avenue, Toronto, ON M5G 1X8, Canada.

Received: 27 August 2014 Accepted: 7 January 2015

Published online: 18 February 2015

\section{References}

1. Piquilloud L, Vignaux L, Bialais E, Roeseler J, Sottiaux T, Laterre PF, et al. Neurally adjusted ventilatory assist improves patient-ventilator interaction. Intensive Care Med. 2011;37:263-71.

2. Spahija J, de Marchie M, Albert M, Bellemare P, Delisle S, Beck J, et al. Patient-ventilator interaction during pressure support ventilation and neurally adjusted ventilatory assist. Crit Care Med. 2010;38:518-26.

3. Colombo D, Cammarota G, Alemani M, Carenzo L, Barra FL, Vaschetto R, et al. Efficacy of ventilator waveforms observation in detecting patientventilator asynchrony. Crit Care Med. 2011;39:2452-7.

4. Colombo D, Cammarota G, Bergamaschi V, De Lucia M, Corte FD, Navalesi P. Physiologic response to varying levels of pressure support and neurally adjusted ventilatory assist in patients with acute respiratory failure. Intensive Care Med. 2008;34:2010-8.

5. Terzi N, Pelieu I, Guittet L, Ramakers M, Seguin A, Daubin C, et al. Neurally adjusted ventilatory assist in patients recovering spontaneous breathing after acute respiratory distress syndrome: physiological evaluation. Crit Care Med. 2010;38:1830-7.

6. Breatnach C, Conlon NP, Stack M, Healy M, O'Hare BP. A prospective crossover comparison of neurally adjusted ventilatory assist and pressuresupport ventilation in a pediatric and neonatal intensive care unit population. Pediatr Crit Care Med. 2010;11:7-11.

7. Wu XY, Huang YZ, Yang Y, Liu SQ, Liu HG, Qiu HB. Effects of neurally adjusted ventilatory assist on patient-ventilator synchrony in patients with acute respiratory distress syndrome. Zhonghua Jie He He Hu Xi Za Zhi. 2009;32:508-12. Chinese.

8. Piquilloud L, Tassaux D, Bialais E, Lambermont B, Sottiaux T, Roeseler J, et al. Neurally adjusted ventilatory assist (NAVA) improves patient-ventilator interaction during non-invasive ventilation delivered by face mask. Intensive Care Med. 2012;38:1624-31.

9. Schmidt M, Dres M, Raux M, Deslandes-Boutmy E, Kindler F, Mayaux J, et al. Neurally adjusted ventilatory assist improves patient-ventilator interaction during postextubation prophylactic noninvasive ventilation. Crit Care Med. 2012;40:1738-44

10. Mauri T, Bellani G, Grasselli G, Confalonieri A, Rona R, Patroniti N, et al. Patient-ventilator interaction in ARDS patients with extremely low compliance undergoing ECMO: a novel approach based on diaphragm electrical activity. Intensive Care Med. 2013;39:282-91.

11. de la Oliva P, Schüffelmann C, Gómez-Zamora A, Villar J, Kacmarek RM. Asynchrony, neural drive, ventilatory variability and COMFORT: NAVA versus pressure support in pediatric patients. A non-randomized cross-over trial. Intensive Care Med. 2012;38:838-46.

12. Grasselli G, Beck J, Mirabella L, Pesenti A, Slutsky AS, Sinderby C. Assessment of patient-ventilator breathe contribution during neurally adjusted ventilatory assist. Intensive Care Med. 2012:38:1224-32.

13. Baydur A, Behrakis PK, Zin WA, Jaeger M, Milic-Emili J. A simple method for assessing the validity of the esophageal balloon technique. Am Rev Respir Dis. 1982;126:788-91. 
14. Doorduin J, Sinderby CA, Beck J, Stegeman DF, van Hees HW, van der Hoeven JG, et al. The calcium sensitizer levosimendan improves human diaphragm function. Am J Respir Crit Care Med. 2012;185:90-5.

15. Beck J, Sinderby C, Lindström L, Grassino A. Effects of lung volume on diaphragm EMG signal strength during voluntary contractions. J Appl Physiol. 1998;85:1123-34.

16. Beck J, Gottfried SB, Navalesi P, Strobik Y, Comtois N, Rossini M, et al. Electrical activity of the diaphragm during pressure support ventilation in acute respiratory failure. Am J Respir Crit Care Med. 2001;164:419-24.

17. Yan S, Sinderby C, Bielen P, Beck J, Comtois N, Sliwinski P. Expiratory muscle pressure and breathing mechanics in chronic obstructive pulmonary disease. Eur Respir J. 2000;16:684-90.

18. Ninane V, Yernault JC, de Troyer A. Intrinsic PEEP in patients with chronic obstructive pulmonary disease: role of expiratory muscles. Am Rev Respir Dis. 1993;148:1037-42.

19. Lessard MR, Lofaso F, Brochard L. Expiratory muscle activity increases intrinsic positive end-expiratory pressure independently of dynamic hyperinflation in mechanically ventilated patients. Am J Respir Crit Care Med. 1995;151:562-9.

20. Sinderby C, Beck J, Spahija J, de Marchie M, Lacroix J, Navalesi P, et al. Inspiratory muscle unloading by neurally adjusted ventilatory assist during maximal inspiratory efforts in healthy subjects. Chest. 2007;131:711-7.

21. Viale JP, Duperret S, Mahul P, Delafosse B, Delpuech C, Weismann D, et al. Time course evolution of ventilatory responses to inspiratory unloading in patients. Am J Respir Crit Care Med. 1998;157:428-34

22. Schmidt M, Demoule A, Cracco C, Gharbi A, Fiamma MN, Straus C, et al. Neurally adjusted ventilatory assist increases respiratory variability and complexity in acute respiratory failure. Anesthesiology. 2010;112:670-81.

23. Liu L, Liu H, Yang Y, Huang Y, Liu S, Beck J, et al. Neuroventilatory efficiency and extubation readiness in critically ill patients. Crit Care. 2012;16:R143.

24. Brander L, Leong-Poi H, Beck J, Brunet F, Hutchison SJ, Slutsky AS, et al. Titration and implementation of neurally adjusted ventilatory assist in critically ill patients. Chest. 2009;135:695-703.

\section{Submit your next manuscript to BioMed Central and take full advantage of:}

- Convenient online submission

- Thorough peer review

- No space constraints or color figure charges

- Immediate publication on acceptance

- Inclusion in PubMed, CAS, Scopus and Google Scholar

- Research which is freely available for redistribution 